\title{
A therapeutic approach to atopic eczema
}

\section{PC Potter MD, FCP(SA), DCH(SA)}

To cite this article: PC Potter MD, FCP(SA), DCH(SA) (2010) A therapeutic approach to atopic eczema, South African Family Practice, 52:4, 277-282, DOI: 10.1080/20786204.2010.10873990

To link to this article: http://dx.doi.org/10.1080/20786204.2010.10873990

(c) 2010 SAAFP. Published by Medpharm.

曲 Published online: 15 Aug 2014.

Submit your article to this journal $x$

Џlll Article views: 246

Q View related articles $\square$

4 Citing articles: 2 View citing articles 


\title{
A therapeutic approach to atopic eczema
}

\author{
Potter PC, MD, FCP(SA), DCH(SA) \\ Allergy Diagnostic and Clinical Research Unit, Department of Medicine, \\ University of Cape Town Lung Institute and Groote Schuur Hospital, Cape Town, South Africa \\ Correspondence to: Dr Paul Potter, e-mail: Paul.Potter@uct.ac.za
}

Keywords: atopic eczema

\begin{abstract}
Atopic eczema is a common problem in general practice. The underlying disorder is a barrier dysfunction of the skin, but exacerbations of eczema can be triggered by a range of external and internal factors. In young children, dietary factors are important triggers of exacerbations and specific IgE sensitivity to common allergens may be confirmed by skin prick testing or ImmunoCap ${ }^{\circledR}$ RAST tests.

True sensitivity to foods is best confirmed by a controlled food challenge, and cut off values have been published which indicate the predictive values of blood or skin tests for true food sensitivity to guide the clinician.

Elimination of identifiable triggers, the use of emollients and topical corticosteroids remain the mainstay of treatments.

Calcineurin inhibitors have a place for treatment of selected cases. The use of systemic corticosteroids is discouraged and patients who do not respond to emollients, specific food avoidance and corticosteroids topically should be referred to a dermatologist. The role of maternal diet in preventing the development of eczema in the offspring remains controversial.
\end{abstract}

(P) Peer reviewed. (Submitted: 2010-02-18, Accepted: 2010-08-06). ๑ SAAFP

SA Fam Pract 2010;52(4):277-282

\section{Introduction}

Atopic eczema is an inflammatory disorder of the skin characterised by pruritis, a typical distribution of eczematous skin lesions, a chronic relapsing course and a personal or family history of atopic disease. ${ }^{1}$

The disease often begins early in infancy. Although there is a paucity of data on the prevalence of atopic eczema in South Africa, the International Study of Asthma and Allergies in Children (ISAAC) Phase I study reported a prevalence of $5-10 \%$ in Cape Town school children. ${ }^{2}$ Eczema is the most common cause for consultation with a dermatologist. The condition may be triggered by a range of external and internal factors, acting singly, or in combination. Not all eczematous skin diseases are atopic. Table I provides a list of the different forms of eczematous skin diseases. ${ }^{1}$

In Figure 1, the World Allergy Organization (WAO) classification of eczema/dermatitis illustrates how atopic eczema fits into the general spectrum of dermatitis. ${ }^{3}$ This article will deal specifically with elements in the management of the allergic aspects of atopic eczema, although the principles of overall management are the same for both atopic and non-atopic eczema.
Table I: Eczematous skin diseases

\begin{tabular}{l|l|l|}
\hline \multicolumn{2}{|c}{ Classification of eczematous skin diseases } \\
\hline Disease & Feature \\
\hline Allergic contact dermatitis & $\begin{array}{l}\text { Provoked by local contact with allergen } \\
\text { Haematogenous/drug induction possibly } \\
\text { with allergen }\end{array}$ \\
\hline Photoallergic dermatitis & $\begin{array}{l}\text { Provoked by local contact plus UV } \\
\text { radiation } \\
\text { Haematogenous/drug induction possibly }\end{array}$ \\
\hline $\begin{array}{l}\text { Atopic dermatitis/ } \\
\text { neurodermatitis }\end{array}$ & $\begin{array}{l}\text { Extrinsic type (i.e. atopic dermatitis) } \\
\text { Intrinsic type (i.e. neurodermatitis) }\end{array}$ \\
\hline Irritant contact dermatitis & \begin{tabular}{l} 
Provoked by local contact \\
\hline Phototoxic dermatitis
\end{tabular} & $\begin{array}{l}\text { Provoked by local contact plus UV } \\
\text { radiation }\end{array}$ \\
\hline Seborrhoeic dermatitis & $\begin{array}{l}\text { Provoked by Malassezia sympodialis plus } \\
\text { endocrine factors }\end{array}$ \\
\hline $\begin{array}{l}\text { Nummular dermatitis/ } \\
\text { discoid eczema }\end{array}$ & $\begin{array}{l}\text { Provoked by inflammatory focus } \\
\text { Varicosis dermatitis/stasis } \\
\text { eczema }\end{array}$ & $\begin{array}{l}\text { Provoked by a state of chronic venous } \\
\text { insufficiency }\end{array}$ \\
\hline
\end{tabular}

The term "eczema" describes an aggregation of several skin diseases with clinical characteristics which involve a genetically determined skin barrier defect. Addressing the barrier defect dysfunction is thus the foundation of management for all forms of eczema. ${ }^{4}$ 


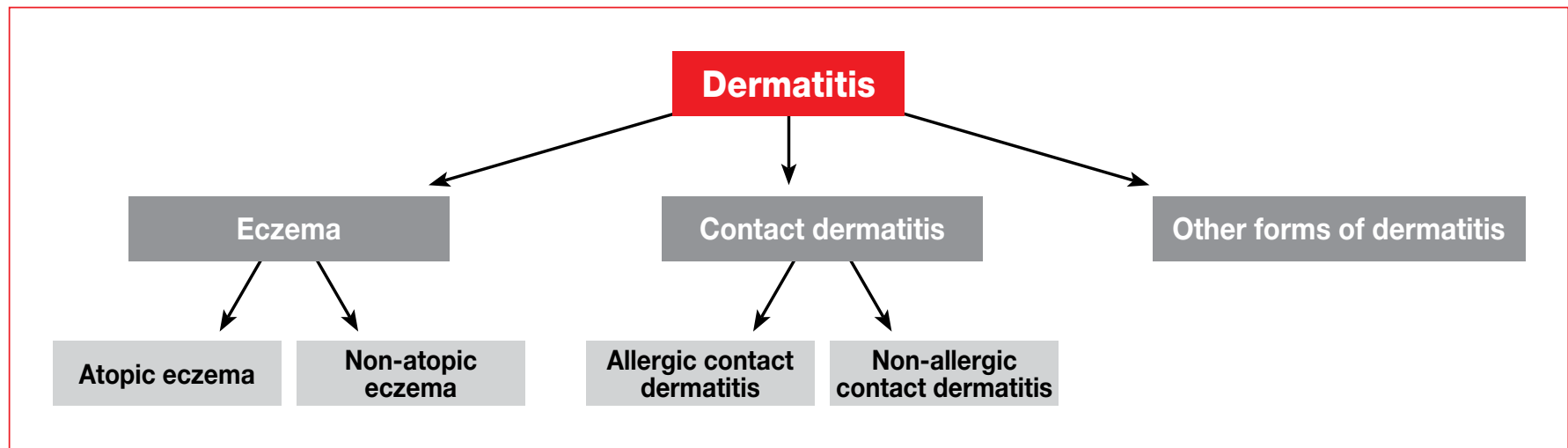

Figure 1: The new World Allergy Organization (WAO) classification of eczema/dermatitis (2004) $)^{3}$

Although atopic eczema is more frequently seen in affluent communities, a South African study conducted by Todd et $\mathrm{al}^{5}$ among Xhosa children found a point prevalence of dermatologist-diagnosed eczema of $0.7 \%, 1.1 \%$ and $3.7 \%$ in rural, peri-urban and urban settings, respectively.

\section{Pathophysiology}

There is increasing evidence that $\mathrm{T}$ cell responses to environmental or food allergens are important in the pathogenesis of atopic eczema. ${ }^{1}$ The extrinsic variant, with sensitivity to food and inhalants is found in about $25-30 \%$ of eczema patients overall, but more commonly identified in younger children and in infants with atopic eczema (about $60 \%) .{ }^{4}$ The intrinsic variant has all the typical features of atopic dermatitis in the absence of elevated IgE levels. T cells may play a more dominant role in the intrinsic group, but both groups have a significant barrier defect.

In the extrinsic type the total IgE may be markedly elevated (more than $1000 \mathrm{kU} / \mathrm{L}$ ). Neural factors such as acetylcholine and substance $\mathrm{P}$ also play a role and some patients experience exacerbations when exposed to nonspecific (e.g. temperature, sunlight) as well as specific triggers, such as food and inhalants. $^{1}$

\section{Patterns of reactions to foods}

At least three cutaneous patterns are recognised following an oral challenge with a food in patients with eczema. ${ }^{6}$

Type I is an immediate reaction, such as urticaria, angioedema and erythema, occurring within minutes of ingestion. In addition, gastrointestinal, respiratory and cardiovascular symptoms may evolve. This is a typical Type I Gell and Coombs reaction, usually $\lg$ E mediated.

Type II is a pruritis reaction which occurs soon after ingestion (within an hour) and is followed by scratching and an exacerbation of the eczema, often lgE mediated.

Type III is a late reaction occurring 6-18 hours after ingestion, manifesting as an exacerbation of atopic dermatitis usually not dominantly IgE mediated, but may involve $\mathrm{T}$ cells, IgE epsilon bearing Langerhans cells and mast cells.

\section{Diagnostic considerations}

Factors which assist the clinician to make a clinical diagnosis include a family history, the presence of pruritis affecting the flexural area of the arms, knees, behind the neck or on the face, onset before the age of two years, other atopic disease (e.g. asthma, rhinitis, food allergy) and usually a good response to topical steroids (within a few days) and a poor relief of itching following non-sedating antihistamines. ${ }^{4}$

\section{Prevalence of allergy in atopic dermatitis}

Sicherer et $\mathrm{al}^{7}$ confirmed food allergy in $60 \%$ of a selected population of children with atopic dermatitis. The clinical profile of an exacerbation by food depends on whether the eczema is in an active phase or in remission.

A double-blind placebo-controlled food challenge (DBPCFC) in children in remission resulted in pruritis and urticaria, whereas a DBPCFC conducted in children with active disease resulted in eczematous eruptions. ${ }^{8}$

Food allergy is more likely to be present in more severe disease, particularly in children. ${ }^{9}$

Identifying food as a relevant trigger in the presence of a positive specific IgE test is relatively easy when the reaction follows soon after ingestion of the allergen.

It is however much more difficult to completely attribute delayed reactions to foods. For such reactions the clinician looks for an eczematous response occurring 4-6 hours after ingestion of the food. For challenge purposes the suspected food should be given over a period of two days after two challenge-free days. Guidelines for challenge procedures in children have been published by Bindslev-Jensen ${ }^{10}$ in a European Academy of Allergy and Clinical Immunology position statement.

In patients with atopic eczema who are sensitive to house dust mites, intensive house dust mite avoidance measures, including hot washing of the bed at $60^{\circ} \mathrm{C}$ and the application of mite impermeable bed, mattress and duvet covers play an important role in reducing the severity of symptoms. 


\section{Confirmation of the diagnosis of food allergy}

The diagnosis is suggested by a detailed history followed by careful skin prick tests or ImmunoCap ${ }^{\circledR}$ RAST tests. Confirmation of the diagnosis may be made by open or doubleblind placebo-controlled food challenge.

To avoid conducting unnecessary food challenges it is useful, in children with eczema, to apply the $100 \%$ cut off values for skin prick tests ${ }^{9}$ or Cap RAST tests ${ }^{8}$ which will predict a positive food challenge (see Tables II and III).

Table II: Positive predictive values for skin prick tests (for open food challenge $)^{9}$

\begin{tabular}{|l|c|c|}
\hline & Older children & Infants $\leq \mathbf{2}$ years \\
\hline Cow's milk & $8 \mathrm{~mm}$ & $6 \mathrm{~mm}$ \\
\hline Eggs & $7 \mathrm{~mm}$ & $5 \mathrm{~mm}$ \\
\hline Peanuts & $8 \mathrm{~mm}$ & $4 \mathrm{~mm}$ \\
\hline
\end{tabular}

Table III: Specific IgE predictive values (for positive food challenges) ${ }^{6}$

\begin{tabular}{|l|c|c|}
\hline Allergen & kU/L & PPV \\
\hline Eggs $^{*}$ ( $\mathbf{2}$ years) & 7 & 98 \\
\hline Milk* (> 2 years) & 15 & 95 \\
\hline Peanuts & 14 & 100 \\
\hline Fish & 20 & 100 \\
\hline Tree nuts & 15 & 95 \\
\hline Soy bean & 30 & 73 \\
\hline Wheat & 26 & 74 \\
\hline
\end{tabular}

${ }^{*}$ For children less than two years, cut off values for egg and milk are $2 \mathrm{kU} / \mathrm{L}$ and $5 \mathrm{kU} / \mathrm{L}$ with a $95 \%$ positive predictive value respectively ${ }^{6}$ PPV: positive predictive value

Although the cut off values for wheal size or lgE level are highly predictive for positive challenge results some patients with lower values may also react with a positive challenge. The positive predictive value for eczematous reactions is $33 \%$ and $77 \%$ for other immediate reactions to the food challenge ${ }^{11}$. The diagnostic significance of specific lgE values appears to be greater in children under 2 years, after which many eczema children "outgrow" their clinical sensitivity to the allergen, and specific $\lg E$ values fall with time.

A proper understanding of the indications and limitations of the ImmunoCap ${ }^{\circledR}$ values and skin prick testing results is essential to plan appropriate diets for children with atopic eczema. A negative open challenge will confirm the absence of food allergy and a positive double-blind placebo-controlled food challenge will irrefutably confirm clinical allergy suggested by the results of testing. If one considers the result of every immunologically positive test result to be clinically significant, there is a real danger of restricting many important foods unnecessarily leading to poor nutrition, especially in young children.

Previous evidence ${ }^{7}$ suggested that in high risk families for allergies, exclusive breastfeeding would reduce the development of atopic eczema. However, local studies conducted in poor urban South Africans indicate that the protective effects of breastfeeding are overridden by a strong maternal history of allergy, i.e. breastfeeding tends to protect the development of allergy in non-allergic but not in allergic families. ${ }^{12}$

If mothers are unable to breast feed, a completely hydrolysed formula feed (e.g. Alfare ${ }^{\circledR}$ Nutramigen $^{\circledR}$ ) is recommended to prevent sensitisation. A partially hydrolysed formula such as Nan- $-A^{\circledR}$ may also be given. However the mother should also avoid ingestion of cow milk proteins.

There is no evidence ${ }^{13}$ that substitution of breast milk with soya milk will prevent allergic sensitisation. However, in children with established and confirmed cow milk allergy, soya may be used as a good substitute for cow milk.

The importance in identifying whether the child with eczema has atopic disease and is sensitised to food with elevated specific $\operatorname{lgE}$, lies in the fact that $30 \%$ of these infants are likely to follow an "atopic march", going on to develop allergic rhinitis and allergic asthma. Early avoidance of inhalant allergen (e.g. dust mite) exposure in such infants may be beneficial. In a recent study there was no evidence that treatment of eczema infants with cetirizine will prevent the development of asthma, but there was a preventive effect on the development of urticaria. ${ }^{14}$

\section{Treatment of atopic eczema}

\section{General principles}

These include avoidance of known trigger factors, prevention of drying of the skin and specific anti-inflammatory therapy.

The South African Childhood Consensus document ${ }^{4}$ reported consensus in applying the following measures:

(a) Avoid overheating and external irritants.

(b) Keep the skin covered with clothing to reduce irritants and trauma from scratching. Many exacerbations are induced by bacterial infection, particularly staphylococcus aureus and topical and systemic antibodies may be required when exacerbations are severe.

(c) Avoid irritants such as astringents and soaps.

(d) Avoid wool clothing or clothing with high texture or occlusive properties, cotton being preferable.

(e) Avoid excessive hand washing.

(f) Regular bathing assists in the hydration of the skin.

(g) Use a moisturising cleanser such as HEB rather than antibacterial cleansers. Aqueous creams may cause cooling through evaporation and may be more soothing in acute flare ups. Ointments stick longer.

(h) Apply emollients immediately after bathing.

(i) Avoid foods to which the child has clinically relevant sensitivity.

(j) Apply house dust mite measures on the bedding and floors for those sensitised to house dust mites. 


\section{Emollients}

Although the literature lacks evidenced-based publications on the use of emollients, opinion base is strong on their value as first line agents for the topical management of children and adults with eczema, to address the barrier defect present in all eczema children and to prevent dryness of the skin.,15

Ointments and creams are preferred over lotions and should be applied frequently, at least four times in a 24-hour period. Sufficient quantities need to be supplied, e.g. $250 \mathrm{~g} /$ week for children and $500 \mathrm{~g} /$ week for adults to cover the whole body.

Slight burning may occur, however, with the urea containing products. Some with severe disease will benefit from wet wraps especially at night, where emollients are combined with topical steroids.

\section{Topical steroids}

Topical steroids confer significant benefit to patients with atopic eczema. There are many different topical steroid products with different strengths, making it difficult to compare different steroids. Table IV compares the potency of common different topical steroids ${ }^{4}$ available in South Africa.

Table IV: Degree of potency of topical cortisone preparations ${ }^{4}$

\begin{tabular}{|c|c|c|}
\hline Mild strength & Moderate strength & Potent strength \\
\hline Mylocort ${ }^{\circledR}$ & Advantan $^{\circledast}$ & Dermovate $^{\circledR}$ \\
\hline Procutan $^{\circledR}$ & Elocon $^{\circledR}$ & Diprolene $^{\circledR}$ \\
\hline \multirow[t]{6}{*}{ Stopitch $^{\circledast}$} & Locoid $^{\circledR}$ & Nerisone Forte ${ }^{\circledR}$ \\
\hline & Synalar ${ }^{\circledR}$ & \\
\hline & Betnovate $^{\circledast}$ & \\
\hline & Persivate $^{\circledR}$ & \\
\hline & Diprosone $^{\circledR}$ & \\
\hline & Nerisone ${ }^{\circledR}$ & \\
\hline
\end{tabular}

It is important to bear in mind that the vehicle used for a topical steroid may enhance its efficacy (e.g. fatty base) and that topical steroids are all effective if used once daily. There is no evidence to confirm that skin thinning is a problem with the correct use of topical corticosteroids. Creams are generally preferred for treatment of the face.

It is recommended that mild to mid-potency topical steroids should be used in conjunction with emollients as standardised disease management and that more potent steroids should be used for relief of acute flares for shorter periods. ${ }^{3}$

For young children, a 1\% hydrocortisone cream is advised for mild to moderate eczema, especially for the face. To maintain control, once a remission has been induced, topical steroids can be used twice weekly. High potency steroids are also indicated for areas of lichenification of the skin. As inflammation subsides, use less topical steroids and more moisturiser. It is preferable to apply corticosteroids immediately after bathing. Steroids supplied in a fatty base are particularly useful for the treatment of very dry areas, especially on the knees and lower legs and in chronic cases with very dry skin.
Adverse events to corticosteroids include cutaneous skin atrophy, telangiectasia, hypopigmentation, steroid acne, increased hair growth and rosacea-like reactions. ${ }^{4,16}$ Systemic side effects such as suppression of the hypothalamic pituitary adrenal axis, growth retardation, glaucoma, cataract and Cushing's syndrome are rare.

\section{Antihistamines}

The value of antihistamines in atopic dermatitis is debated. Patients usually obtain minimal or no relief of pruritis from the use of non-sedating antihistamines. Some patients derive relief from the use of sedating antihistamines, such as Aterax ${ }^{\circledR}$ (Hydroxyzine $25 \mathrm{mg}$ ) (or $1 \mathrm{mg} / \mathrm{kg} / 24 \mathrm{hrs}$ ) used at night, to ensure a good night's rest and relief of itch. In larger patients, higher doses may be required. Topical antihistamines may cause sensitisation and should thus be avoided.

\section{Calcineurin inhibitors}

Pimecrolimus has been approved in South Africa for shortterm treatment of "flare ups for atopic eczema in children over the age of 2 years". ${ }^{4}$ Short-term treatment followed concerns that resulted in a black box warning by the FDA, until further long-term surveillance studies have been completed. Five year surveillance studies on safety have been completed and publications of these studies are awaited. Patients on pimecrolimus require adequate sun protection creams as well.

Tacrolimus is registered for the treatment of eczema in South Africa, and experience with this non-steroidal topical eczema treatment is promising. Steroid phobia is a recognised problem in patients with eczema and calcineurin inhibitors do provide an alternative for selected patients.

\section{Other specialised treatments for eczema}

Although there are few studies focussing on the clinical efficacy of tar preparations in the treatment of eczema, they may be effective if administered topically or in a bath tub, ${ }^{11}$ however cosmetic side effects may affect compliance with such preparations.

Phototherapy may also be used under the supervision of a specialist dermatologist for the management of severe cases of eczema and is available as conventional UVA/UVB combination therapy, UVA therapy, photo chemotherapy with methoxsalen plus UVA (PUVA) and narrowband UVB (312 nm). PUVA therapy may be associated with severe side effects including the development of cutaneous neoplasms. ${ }^{3}$

Cyclosporin is also effective for the treatment of severe atopic eczema and may induce prompt relief of symptoms, but relapses are common, after stopping therapy. It may be given in 12 week cycles with at least seven days between each course to achieve a lower cumulative dose. It is important that renal function is carefully monitored. ${ }^{17}$

Systemic corticosteroids are known to be effective in the short term for atopic eczema, but their use is invariably followed by 
rebound flare ups and there are significant dangers of systemic steroid side effects with long term use. Toxicity also limits the potential use of azathiaprine, or interferon gamma and none of these three treatments should be prescribed by a general practitioner. Treatment with gamma interferon is still regarded as experimental.

Probiotics such as lactobacillus rhamnosis (ATCC 53103) administered to at-risk infants in the first two years of life has been reported to reduce the risk of development of atopic eczema. ${ }^{18}$ More studies are needed and a firm general recommendation for the early use of probiotics to prevent eczema in high risk families cannot be made. ${ }^{4}$

Systemic antibiotic treatment is indicated for widespread secondary bacterial infection primarily $S$. aureus. First or second generation cephalosporins or semi synthetic penicillins for 7-10 days are usually effective. Erythromycin- resistant organisms are fairly common making macrolides less useful alternatives. ${ }^{19}$ In cases of penicillin or cephalosporin allergy, clindamycin or oral fusidic acid are possible alternatives. ${ }^{20}$

\section{Maternal diet and prevention of eczema}

There is ongoing debate as to whether breastfeeding is protective for the development of atopic eczema in the offspring. In a recent study by Yan et $\mathrm{al}^{21}$ sensitisation to egg was higher in a breast fed group compared to a formula-fed group of infants. In another recent study by Saito et al ${ }^{22}$ it was found that higher maternal meat intake may increase the risk of infantile atopic eczema and that there was no evidence that maternal intake of fish and n-3 polyunsaturated fatty acids protected against infantile atopic eczema.

\section{Treatments with no proven benefit}

Although exposure to house dust mites may exacerbate eczema flares in patients sensitised to house dust mites, there is no evidence that allergen immunotherapy is beneficial either by the subcutaneous or sublingual route. ${ }^{3}$ However, new studies on this are in progress.

Likewise, Chinese herbal medicine, ingestion of unsaturated fatty acids (e.g. evening primrose oil), homoeopathy, acupuncture, climatotherapy, African traditional medicine and massage therapy have no evidence-based efficacy and are thus not recommended for the treatment of atopic eczema. ${ }^{4}$

\section{References}

1. Weifel T, Kapp A. Atopic dermatitis and allergic contact dermatitis in Allergy. Eds Holgate ST, Church MK, Liechtenstein LM. Mosby, Elsevier 2006; Chapter 7:107-127.

2. Williams $\mathrm{H}$, Robertson $\mathrm{C}$, Stewart $\mathrm{A}$ et al. Worldwide variations in the prevalence of symptoms of atopic eczema in the International Study of Asthma and Allergies in Childhood. J Allergy Clin Immunol 1999;103:125-138.

3. Johannson SGO, Bieber B, Dahl R, Friedman PS, Lanier BQ, Lockey RF, Motala C, Ortego JA, Platts-Mills TAE, Ring J, Thien F, Van Crauwenberge P, Williams HC. Revised nomenclature for allergy for global use. Report of the Nomenclature Review Committee of the World Allergy Organization. J Allergy Clinical Immunology, 2004;113:832-836.

4. Manjra Al, Du Plessis P, Weiss R, Motala C, Potter PC, Rabobee N, Ndlova N, Davier M, Weinberg EG. Childhood atopic eczema consensus document. S Afr Med J 2005;95(6):435-440

5. Todd G, Saxe N, Milne J, Tolosana S, Williams H. Prevalence of atopic dermatitis in children living in rural, peri-urban and urban areas. Curr Allergy Clin Immunology 2004;17:140

6. Potter PC. Atopic eczema in infants: investigations and management. MIMS Disease Review, 2006:7-12.

7. Sicherer SH, Sampson HA. Food hypersensitivity and atopic dermatitis, pathophysiology, epidemiology, diagnosis and management. J Allergy Clin Immunology 1999;104:3(2):S114-S112.

8. Sampson HA. Food sensitivity and the pathogenesis of atopic dermatitis. JR Soc Med 1997;90:2-8

9. Hill D. Food allergy and atopic dermatitis: an epidemiological study. Paediatric Allergy Immunol 2004;15:421-427.

10. Bindslev-Jensen C. Standardization of food challenges in patients with immediate reactions to foods. Allergy 2004;59:690-697.

11. Weifel T, Breuer K. The role of allergy in atopic dermatitis. Current Opinion in Allergy and Clinical Immunology 2004;4:379-385.

12. Obihara C, Beyers N, Potter PC, Kimpen J. The association of prolonged breastfeeding and allergic disease in poor urban children. Eur Resp $J$ 2005;25:970-977

13. Osborne DA, Sinn J. Soy formula for the prevention of allergy and food intolerance in infants. Cochrane Database Systematic Reviews, 2006;Oct, 18(4):CD003741.

14. Simons ER. H1 antihsitamine treatment in young atopic children: effect on urticaria. Ann Allergy Asthma Immunol, 2007;99:261-266.

15. Eichenfield LF, Hanifin JM, Luger TA, Stevens SR, Pride HB. Consensus conference on paediatric atopic dermatitis. J Acad Dermatol 2003;49:1088-1095.

16. Sinclair W, Aboobaker J, Jordaan F, Modi D, Todd G. Management of atopic dermaitits in adolescents and adults in South Africa. S Afr Med J, 2008:98:301-320.

17. Harper JL, Ahmed L, Barclay G, Lacouv M, Hoeger P, Cork MJ. Cyclosporin for severe childhood atopic dermatitis: short course versus continuous therapy. $\mathrm{Br} J$ Dermatol 2000;142:52-58.

18. Hanifin JM, Cooper KD, Ho VC. Guidelines for care for atopic dermatitis. J Am Acad Dermatol 2004;50:391-404.

19. Hoeger PH. Anti-microbial susceptibility of skin-colonising S aureaus strains in children with atopic dermatitis. Pediatr Allergy Immunol, 2004;15:474-477.

20. Adkis CA, Adkis MA, Bieber TB, Bindslev-Jensen C, Eigenmann P, Kapp A, Leung D, Luger T, Platts-Mills T, Rossenwasser L, Simons S, Spergl J, Turjanmaa K, Wahn U, Weifel T, Zuberbeir T. Diagnosis and treatment of atopic dermatitis in children and adults. European Academy of Allergology and Clinical Immunology/ American Academy of Allergy, Asthma and Immunology/Practall Consensus Report. J Allergy Clin Immunol, 2006;118:152-169.

21. Han Youngshin, Chung SJ, Kim Jihyun, Ahn Kangmo, Lee S. High sensitization rate to food allergens in breast fed infants with atopic dermatitis. Ann Allergy Asthma Immunol, 2009;103:332-336

22. Saito K, Yokiyama T, Miyake Y, Sasaki S, Tanaka K, Ohya Y, Hirota Y. Maternal meat and fat consumption during pregnancy and suspected atopic eczema in Japanese infants aged 3-4 months. Pediatric Allergy Immunol, 2010;21:38-46. 